\title{
Microdevice for aqueous humor drainage Maldonado Bas - Pförtner
}

\author{
Microdispositivo para drenaje de humor acuoso Maldonado Bas - Pförtner
}

Arturo Maldonado-Bas ${ }^{1}$, Ana Maldonado-Junyent ${ }^{2}$, Arturo Maldonado-Junyent $^{3}$

\begin{abstract}
Purpose: A microdevice for the treatment of refractory glaucoma is presented. The underlying concepts, its mechanisms of action and the surgical technique for implanting are explained and the results are analyzed. The microdevice was developed and the surgeries were performed at the Maldonado-Bas Eye Clinic (Cordoba, Argentina), under the rules established in the protocol approved by the provisions of the National Administration of Drugs, Food and Medical Technology 430/7. File No.:1-47-25-649-07-1.

Methods: In a prospective study, following the protocol, 16 eyes with refractory glaucoma were included and operated. Intraocular pressure $\leq 21 \mathrm{mmHg}$ with or without additional medication was considered successful. The follow-up was one year. Averages, percentages and their 95\% confidence bands were calculated. Analysis of variance for repeated measures was used to compare averages.

Results: The average preoperative intraocular pressure was $32.81 \mathrm{mmHg}$, SD $\pm 10.94 \mathrm{mmHg}$ in a range of 14 to $50 \mathrm{mmHg}$. The average post-surgical intraocular pressure at one year was $12.43 \mathrm{mmHg}, \mathrm{SD} \pm 2.85 \mathrm{mmHg}$ in a range of 7 to $19 \mathrm{mmHg}$. The difference between the pre-and post-surgery average intraocular pressure was $20.38 \mathrm{mmHg}$. The number of successes was 14 eyes (87.5\%, confidence interval $(\mathrm{Cl})$ $95 \% 61.6 \%-98.6 \%)$. The number of failures was two eyes (12.5\%, Cl 95\% 1.43\%-38.4\%) Conclusions: The results show that the microdevice is successful for the treatment of refractory glaucoma.
\end{abstract}

Keywords: Glaucoma/surgery; Filtering surgery; Intraocular pressure; Trabeculectomy/methods; Aqueous humor; Optical devices; Sclera/surgery; Sclerostomy

\section{RESUMEN}

Objetivo: Se presenta un microdispositivo para el tratamiento del glaucoma refractario. Se explican los conceptos con los que fue desarrollado, su mecanismo de acción, la técnica quirúrgica para implantarlo y se analizan los resultados obtenidos. Realizado en la Clínica de ojos Maldonado-Bas (Córdoba- Argentina), bajo la reglamentación establecida en el protocolo aprobado por disposición de la Administración Nacional de Medicamentos, Alimentos y Tecnología Médica 430/7. Expediente:1-47-25-649-07-1.

Métodos: En un estudio prospectivo, según la reglamentación del protocolo se incluyeron e intervinieron 16 ojos con glaucoma refractario. Se consideró éxito presión intraocular $\leq 21 \mathrm{mmHg}$ con o sin medicación adicional. El seguimiento fue de un año. Se calcularon promedios, porcentajes y sus bandas de confianza del $95 \%$ según estuviera indicado. Para comparar promedios se empleó Análisis de la Varianza para mediciones repetidas.

Resultados: El promedio de la presión intraocular pre-quirúrgica fue de 32,81 $\mathrm{mmHg}$, SD $\pm 10,94 \mathrm{mmHg}$ con un rango entre 14 y $50 \mathrm{mmHg}$. La presión intraocular postquirúrgica promedio al año fue de $12,43 \mathrm{mmHg}, \mathrm{SD} \pm 2,85 \mathrm{mmHg}$ con un rango entre 7 y $19 \mathrm{mmHg}$. La diferencia entre el promedio de la presión intraocular pre y posquirúrgica fue de $20,38 \mathrm{mmHg}$. El número de éxitos fue de 14 ojos $187,5 \%$; IC95\% $61,6 \%$ - 98,6\%). El número de fracasos fue de dos ojos (12,5\%; IC95\% 1,43\% - 38,4\%).

Conclusiones: Los resultados demuestran que el microdispositivo es eficaz para el tratamiento del glaucoma refractario.

Descriptores: Glaucoma/cirugia; Cirugía filtrante; Presión intraocular; Trabeculectomial métodos; Humor acuoso; Dispositivos ópticos; Esclerótica/cirugia; Esclerostomía

\section{INTRODUCTION}

For intraocular pressure (IOP) control in patients with refractory glaucoma, special devices called filter implants are used for glaucoma surgery ${ }^{(1)}$. Molteno ${ }^{(2)}$ with one or two plates The bestis the most known of these is the Molteno(2) with one or two plates, but there are also other models such as the Krupin ${ }^{(3,4)}$, the Baerveldt ${ }^{(5)}$ and the Ahmed ${ }^{(6)}$. All these implants, which can lead to surgical complications ${ }^{(1)}$, are designed to drain the aqueous humor from the anterior chamber towards the conjunctival sub-Tenon's space, forming a filtering bleb around the plate at the height of the eye's equator. The differences are the surface drainage area of the devices and the presence or absence of a valve mechanism.

Non-penetrating deep sclerectomy (NPDS) was described by Fyodorov et al. ${ }^{(7)}$, and Zimmerman et al. ${ }^{(8)}$, as non-penetrating trabeculectomy in 1984 and by Arenas ${ }^{(9)}$ as trabeculectomy ab-externo in 1991. NPDS was then modified by Demailly et al. ${ }^{(10)}$, and Koslov et al. ${ }^{(11)}$, in 1996 as a non-penetrating filtering surgery in which the aqueous humor percolates through the trabecular-Descemet's membrane to the intrascleral space ${ }^{(12,13)}$ (maintained or not with implants).
This technique represents an advance over the classical trabeculectomy which was described by Cairns ${ }^{(14)}$, and by Vasco Posadas ${ }^{(15)}$ as protected filtering, in which after dissecting the superficial scleral flap a piece of deep corneoscleral tissue is removed involving the trabeculae and Schlemm's canal channel and completed with an iridectomy.

The microdevice was developed by taking into account the concept of filtering implants, non-penetrating deep sclerectomy and trabeculectomy, which reduce the intraocular pressure by connecting the anterior chamber with a surgically created intrascleral space.

In the case of the microdevice, the tube connecting the anterior chamber with the intrascleral space ensures filtration of the aqueous humor between the two spaces, while the body of the microdevice, as well as fixing the tube and protecting its distal end from blockage, acts as a permanent space maintainer.

The microdevice is not a filter implant in the classic sense. It partially combines trabeculectomy and NPDS techniques with its own function and location.
Submitted for publication: March 11, 2011

Accepted for publication: May 17, 2011

Study carried out at the Clinica de Ojos Maldonado Bas, Cardoba, Argentina.

Physician, Director Médico, Clínica de Ojos Maldonado Bas, Cordoba, Argentina.

2 Physician, Sub-Jefe del Banco de Córneas, Clínica de Ojos Maldonado Bas. Cordoba, Argentina.

${ }_{3}^{3}$ Physician, Departamento de segmento anterior, Clínica de Ojos Maldonado Bas, Cordoba, Argentina.
Funding: No specific financial support was available for this study.

Disclosure of potential conflicts of interest: A.Maldonado-Bas, None; A.Maldonado-Junyent, None; A.Maldonado-Junyent, None.

Correspondence address: Clinica de Ojos Maldonado Bas. Achával Rodrígues - 544 - Cordoba Argentina -E-mail: malbas@ciudad.com.ar 
The present work reflects the final report submitted to National Administration of Drugs, Food and Medical Technology (ANMAT) in June, 2009, file number: 1-47-9227-09-9.

\section{METHODS}

According to the rules established in the protocol entitled "National open-label, multi-centermulticenter trial to evaluate the safety and efficacy of a microdevice for drainage of aqueous humor in refractory glaucoma", approved by ANMAT provision 430/7 - File: 1-47-25 -649-07-1, sixteen eyes presenting with refractory glaucoma were included and operated with the microdevice (Table 1). Two eyes (12.5\%) were presented neovascular glaucoma and three ones (18.75\%) were glaucoma associated with uveitis. IOP $\leq 21 \mathrm{mmHg}$ with or without additional medication was considered successful. According to the rules established in the protocol the follow-up was one year.

This implant was designed for the treatment of refractory glaucoma, defined as that which does not respond to medical treatment and in which the "Gold Standard" technique (trabeculectomy) cannot be performed, because of the nature of the glaucoma (uveitic, neovascular or chronic congestive glaucoma) or because there are previous failed filtering surgeries, and therefore the evolution of the disease leads inexorably to blindness.

The protocol was approved by the Independent Ethics Committee for Clinical Pharmacology Trials, and the Institutional Health Research Ethics Committee (CIEIS) of the Hospital Nacional de Clínicas of the Universidad Nacional de Córdoba.

\section{Patient inclusion CRiteria:}

1. 21 or older

2. Diagnosis of refractory glaucoma.

3. Failed prior conventional surgery

4. Patients who could not be treated medically or with conventional techniques (trabeculectomy) and/or

5. With neovascular glaucoma, and

6. Patients who have signed the Informed Consent Form (ICF).

\section{EXCLUSION CRITERIA:}

1. Patients who have previously received other valve implants.

2. Subjects with current diagnosis of cancer (although the subjects who have previously had cancer and have proven to be without disease for more than five years are eligible).

3. Subjects who have known hypersensitivity or allergy to multiple antibiotics.
4. Subjects with a history or presence of significant systemic disease that is capable of interfering with study assessments or patient safety.

5. Subjects who have received any other experimental treatment within the past eight weeks, and

6. Patients who present incurable retinal detachment generating hypotonia or suffering from any other condition other than glaucoma whose presence and/or evolution could affect the evaluation of the results.

All patients underwent medical ophthalmological checks including the procedures detailed in table 2.

For IOP analysis, the averages, percentages and their 95\% confidence bands were calculated. Analysis of variance for repeated measures was used to compare means.

\section{Characteristics OF the Microdevice:}

It consists of two parts assembled together: (Figure 1A, 1B)

1. A square elasthane ${ }^{\mathrm{TM}(16)}$ body $5 \times 5 \mathrm{~mm}$ in diameter and $0.3 \mathrm{~mm}$ thick. Each corner has a hole for attachment to the sclera.

2. A portion of silicone tube $10 \mathrm{~mm}$ long, $0.5 \mathrm{~mm}$ in external diameter and $0.3 \mathrm{~mm}$ in internal diameter.

\section{Surgical Procedure:}

1. Dissection of fornix-based conjunctival flap.

2. Dissection of the scleral flap by half its thickness, not less than $6 \times 6 \mathrm{~mm}$ in diameter (Figure 2-A).

3. Paracentesis under the scleral flap using a V-Lance knife, and injection of viscoelastic substance. (Figure 2-B)

4. Placement of the tubular portion of the microdevice which is inserted into the anterior chamber through the paracentesis as performed in Section 3. (Figure 3-A, 3B).

5. The device is sutured to the scleral bed with prolene $10 / 0$ or $9 / 0$ prolene (Figure 4A).

6. Replacement and suture of the scleral flap with 9.0 nylon covering the device with 5 stitches, whether removable or not (Figure 4B).

7. The conjunctival flap is sutured with separate 8.0 silk sutures.

Post-surgical medication consisted of topical antibiotics and steroids (moxifloxacin and dexamethasone) were used for fifteen days in all cases.

\section{RESULTS}

The average preoperative IOP was $32.81 \mathrm{mmHg}, \mathrm{SD} \pm 10.94$ with a range between 14 and $50 \mathrm{mmHg}$. The average post-surgical IOP

Table 1. Patients enrolled in the protocol and their background

\begin{tabular}{cl}
\hline Case & \multicolumn{1}{c}{ History prior to implant of the microdevice } \\
\hline 1 & POAG end stage, pseudophakia, previous failed trabeculectomy. \\
2 & End-stage POAG, malignant myopia, retinal detachment with circular implant, uveitis. \\
3 & End-stage POAG, previous failed trabeculectomy, pseudophakic. \\
4 & Chronic congestive glaucoma. \\
5 & Late congenital glaucoma, end stage. Two previous failed trabeculectomies. \\
6 & Pseudoexfoliative glaucoma, pseudophakia, two previous failed filtering surgeries. \\
7 & Traumatic glaucoma, aphakia, band keratopathy, previous failed trabeculectomy. \\
8 & Uveitis, pseudophakia, two previous failed trabeculectomies, band keratopathy, bullous keratopathy. PainfullPainful blind eye. \\
9 & End-stage POAG, myopia magna, pseudophakia, corneal transplant, failed previous filtering surgery \\
10 & POAG end-stage, prior failed trabeculectomy. \\
11 & Terminal cortisone glaucoma, uveitis, previous failed trabeculectomy. \\
12 & CRVT, NVG. bullous keratopathy. Painful blind eye. \\
13 & CRVT, hemovitreous, NVG. PainfullPainful blind eye. \\
14 & CRVT, previous failed trabeculectomy, pseudophakia. Painful blind eye. \\
15 & End-stage POAG, previous failed trabeculectomy. \\
16 & End-stage POAG, previous failed trabeculectomy, uveitis. \\
\hline
\end{tabular}

$\mathrm{POAG}=$ primary open-angle glaucoma; $\mathrm{CRVT}=$ thrombosis of central retinal vein; $\mathrm{NVG}=$ neovascular glaucoma 
Table 2. Procedure schedule

\begin{tabular}{|c|c|c|c|c|c|c|c|c|c|}
\hline Day * & -7 to -1 & 0 & 2 & 30 & 60 & 90 & 120 & 180 & 360 \\
\hline Visit & 1 & 2 & 3 & 4 & 5 & 6 & 7 & 8 & 9 \\
\hline Informed consent & $x$ & & & & & & & & \\
\hline Demographic data & $x$ & & & & & & & & \\
\hline Inclusion and exclusion criteria & $x$ & & & & & & & & \\
\hline Medical history & $x$ & & & & & & & & \\
\hline Physical examination & $x$ & $x$ & $x$ & $x$ & $x$ & $x$ & $x$ & $x$ & $x$ \\
\hline Visual acuity & $x$ & & $x$ & $x$ & $x$ & $x$ & $x$ & $x$ & $x$ \\
\hline IOP & $x$ & & $x$ & $x$ & $x$ & $x$ & $x$ & $x$ & $x$ \\
\hline Fundus & $x$ & & & $x$ & $x$ & $x$ & $x$ & $x$ & $x$ \\
\hline Refractometry & $x$ & & & $x$ & $x$ & $x$ & $x$ & $x$ & $x$ \\
\hline Biomicroscopy & $x$ & $x$ & $x$ & $x$ & $x$ & $x$ & $x$ & $x$ & $x$ \\
\hline Computerized visual field & $x$ & & & $x$ & & & & & $x$ \\
\hline Pachymetry & $x$ & & & & & & & & \\
\hline Handover patient diary & $x$ & & & & & & & & \\
\hline Concomitant medication & $x$ & $x$ & $x$ & $x$ & $x$ & $x$ & $x$ & $x$ & \\
\hline Implant placement & & $x$ & & & & & & & \\
\hline Adverse events & & $x$ & $x$ & $x$ & $x$ & $x$ & $x$ & $x$ & \\
\hline Daily monitoring of patient & & & $x$ & $x$ & $x$ & $x$ & $x$ & $x$ & $x$ \\
\hline Collection of patient diary & & & & & & & & & $x$ \\
\hline Thanks to the patient & & & & & & & & & $x$ \\
\hline
\end{tabular}

$\mathrm{IOP}=$ intraocular pressure

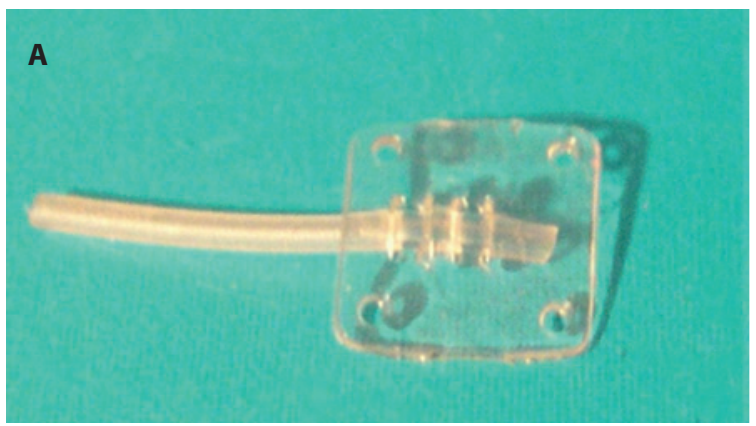

Figura 1. A) Front view of the device; B) Side view of the device.

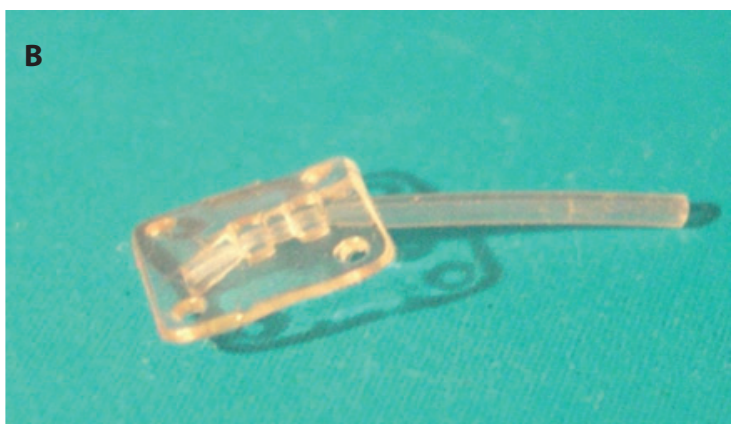

at one year was $12.43 \mathrm{mmHg}, \mathrm{SD} \pm 2.85 \mathrm{mmHg}$ with a range between 7 and $19 \mathrm{mmHg}$.

The difference between mean preoperative and post-surgery IOP was $20.38 \mathrm{mmHg}$.

The success rate was 14 eyes $(87.5 \%, \mathrm{Cl} 95 \%$ 61.6\% - 98.6\%) (Figure 5), of which 2 eyes $(14.3 \%, \mathrm{Cl} 95 \% 1.6$ - 42.9\%) were regulated with additional medication as their IOP was above $21 \mathrm{mmHg}$. Four eyes were regulated without additional medication $(33.3 \%, \mathrm{Cl} 95 \% \mathrm{Cl}$ 9.8 - 65. 2). In 8 eyes (66.7\%, Cl 95\% 34.8 - 90.2\%), medication was indicated even though the IOP was not above $21 \mathrm{mmHg}$ because they showed great damage in the computerized visual field.

The findings support the hypothesis that the use of the microdevice was associated with a significant reduction of IOP. This was confirmed in the analysis of variance for repeated measures ( $F=37.891$, $\mathrm{P}<0.0001)$.

The failure rate was two eyes $(12.5 \%, \mathrm{Cl} 95 \% 1.43$ - 38.4), in one of which the explant of the microdevice was performed because of its extrusion at 120 days. In the review of the surgical technique ${ }_{2}$ it was found that the scleral flap was performed at less than $50 \%$ of the thickness (very thin flap) and the size of the flap was less than $6 \times 6 \mathrm{~mm}$ (very small), so it was considered a failure of surgical technique.

In the other case, the patient voluntarily withdrew from the protocol on day 180 without achieving regulated IOP.

The analysis of computerized visual fields (CVF) using the Brusini glaucoma staging showed: of all patients operated who completed the protocol (14/16 eyes), $35.71 \%$ (5 eyes) improved the CVF by changing its state for one better, $21.42 \%$ (3 eyes) improved the CVF without achieving better staging, 7.14\% (1 eye) demonstrated no changes in the CVF or the staging, 7.14\% (1 eye) showed progression of visual field deterioration and staging, in the remaining $28.57 \%$ (4 eyes) CVF analysis was not performed as they were blind eyes.

In the postoperative examinations with the slit lamp, the filtration bleb was seen to be diffuse in all patients, which was confirmed with ultrasound biomicroscopy studies.

Since the back part of the microdevice is not less than $6 \mathrm{~mm}$ from the limbus, filtration to the subconjunctival space was posterior and the blebs were characteristically diffuse.

Postoperative management of the bleb in patients with microdevice was very similar to that of trabeculectomy, and subconjunctival filtration could be increased with the use of removable sutures.

The complications presented during the course of this investigation (hyphema grade I-II, hypothalamia, proliferation of Tenon's tissue over the scleral flap), were considered to be expected and inherent to any type of filtering surgery (trabeculectomy, NPDS, or filtering implants). The medical and surgical treatments used to solve these complications were the same to solve the complications deriving from these surgeries.

Among the complications in this series, three cases of hyphema were reported, which resolved spontaneously within 72 hours postoperatively without complications. 

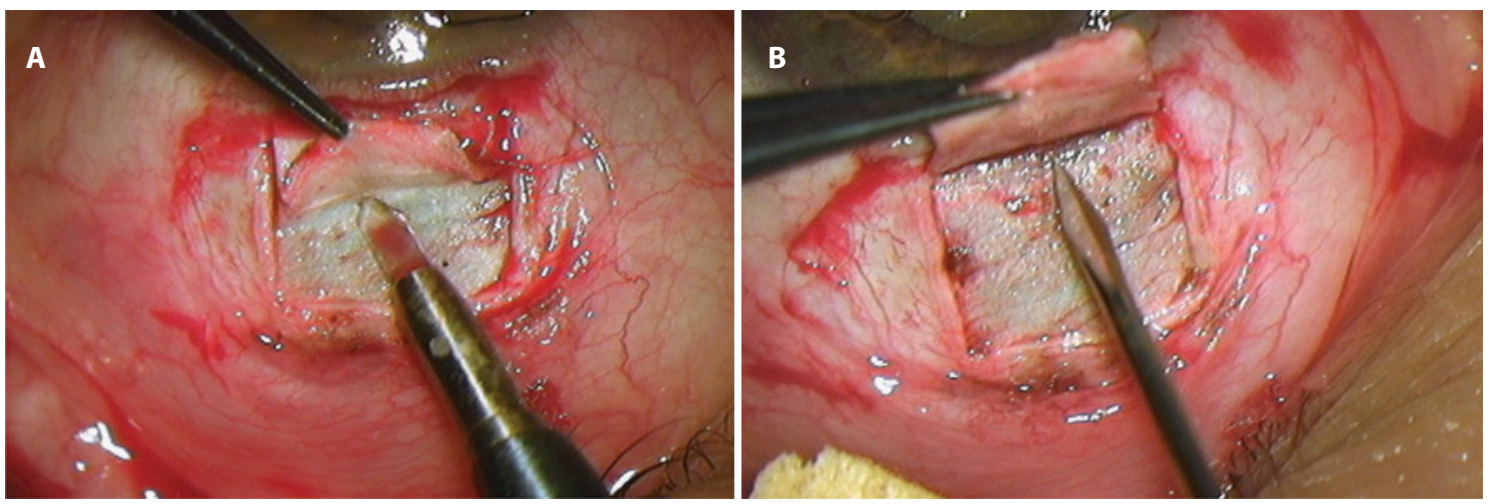

Figura 2. A) Dissection of the scleral flap; B) Paracentesis using a V-lance.
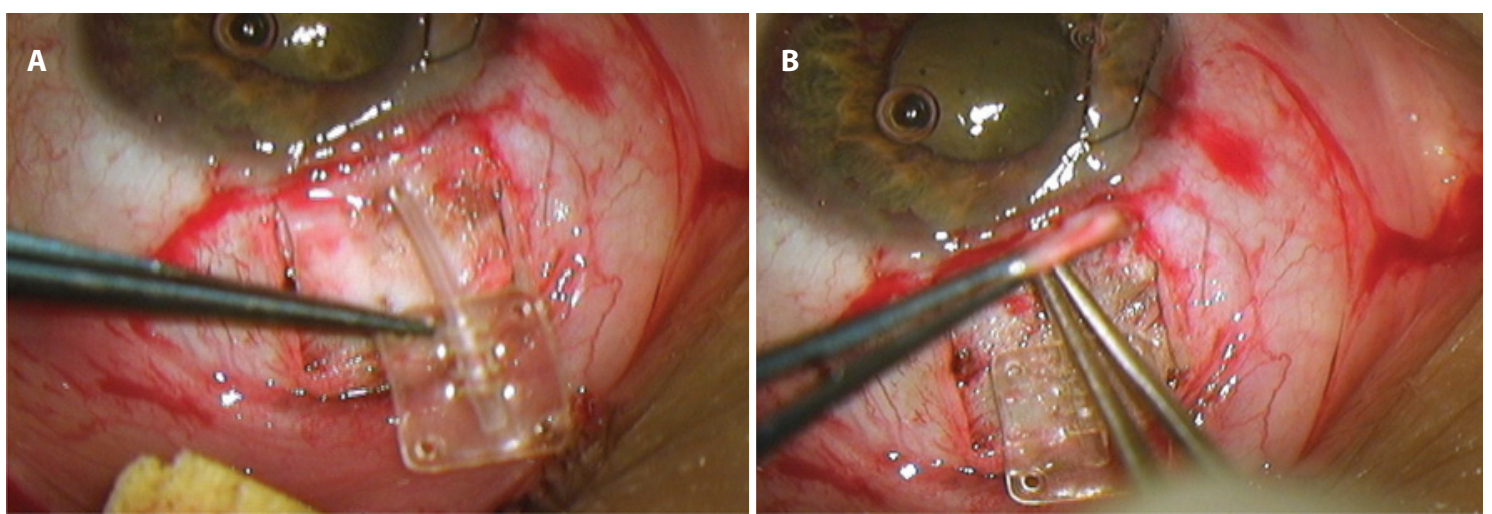

Figura 3. A) Presentation of the device; B) Placement of the device.
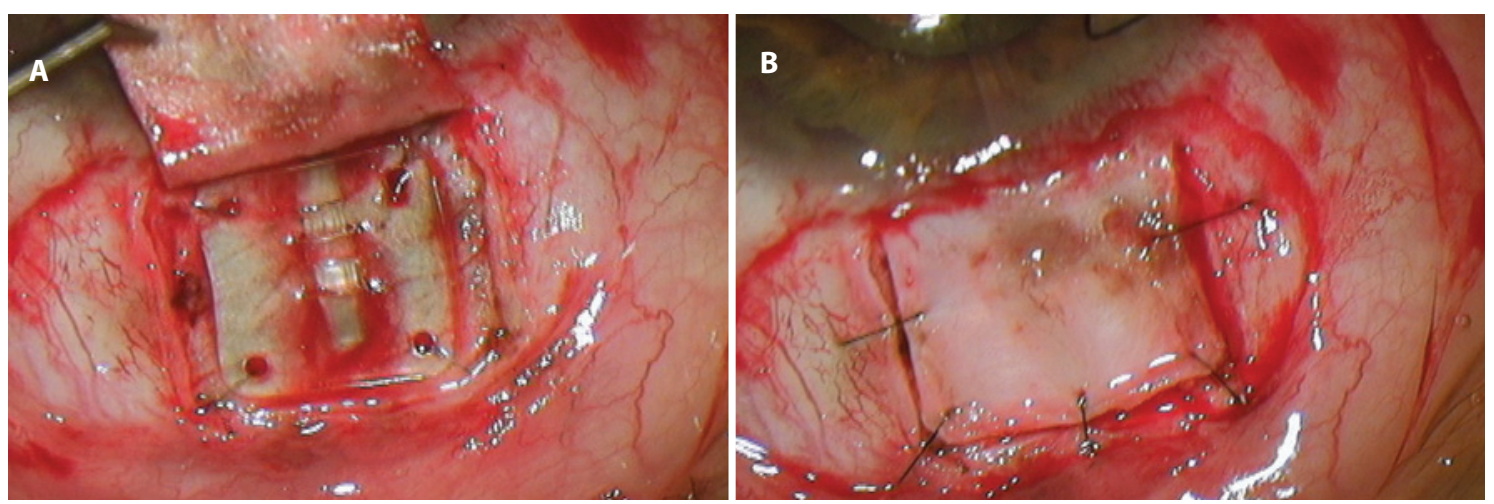

Figura 4. A) Suturing the device to the sclera; B) Closure of the scleral flap.

IOP was $<5$ mmHg at 48 hours postoperatively (Table 2 ) in 7 cases, and gradually increased during the first week post-surgery without additional complications. In two of the seven patients, viscoelastic substance was injected into the anterior chamber 72 hours after surgery for hypothalamia associated with the hypotony.

Obstruction of the mouth of the tube by the iris was reported in one case, in which a surgical iridectomy was performed which and resolved this complication.

After the 120 day check-up, needling was performed in two patients with fluorouracil (5-FU) injection for an encapsulated bleb, which overcame this problem.

\section{DISCUSSION}

The current filtering implants are commonly used to regulate IOP in patients with refractory glaucoma ${ }^{(17)}$. A tube connects the anterior chamber to a plate located in the conjunctival Tenon's space at the level of the equator between the extraocular muscles. The most common and reported complications include: athalamia, postsurgical hypotony, contact of the tube with the cornea, contact of the tube with the iris or lens, choroidal hemorrhage, hyphema, and for its location and size, changes in the palpebral motility and diplopia'. Some authors have reported a hypotonic phase of one week followed by a hypertensive phase (reported in Ahmed, 
Table 3. Patients, age, gender, eye operated, combination microdevices with phacoemulsification, IOP registered in protocol check-ups

\begin{tabular}{|c|c|c|c|c|c|c|c|c|c|c|c|c|}
\hline Case & Age & Gen & Eye & Phaco & Pre IOP & IOP $48 \mathrm{hs}$ & IOP 30 & IOP 60 & IOP 90 & IOP 120 & IOP 180 & IOP 360 \\
\hline 1 & 88 & $M$ & $S$ & no & 35 & 3 & 12 & 21 & 13 & 12 & 10 & 12 \\
\hline 2 & 51 & $M$ & D & yes & 14 & 10 & 15 & 16 & 13 & 12 & 10 & 11 \\
\hline 3 & 72 & M & $S$ & no & 14 & 2 & 14 & 14 & 12 & 10 & 11 & 10 \\
\hline 4 & 63 & $\mathrm{~F}$ & D & yes & 40 & 2 & 13 & 12 & 13 & 12 & 10 & 13 \\
\hline 5 & 37 & $M$ & D & no & 45 & 6 & 16 & 14 & 13 & 14 & 10 & 12 \\
\hline 6 & 68 & $\mathrm{~F}$ & D & no & 34 & 14 & 12 & 10 & 10 & 9 & 10 & 10 \\
\hline 7 & 45 & $\mathrm{~F}$ & D & no & 26 & 17 & 17 & 17 & 16 & 16 & 11 & 14 \\
\hline 8 & 38 & $M$ & S & no & 50 & 5 & 13 & 17 & 15 & 21 & 17 & 19 \\
\hline 9 & 45 & $\mathrm{~F}$ & D & no & 26 & 3 & 10 & 14 & 14 & 14 & 10 & 14 \\
\hline 10 & 80 & $\mathrm{~F}$ & D & yes & 26 & 2 & 13 & 10 & 17 & 10 & 10 & 12 \\
\hline 11 & 20 & $M$ & D & yes & 24 & 7 & 11 & 16 & 10 & 11 & 10 & 16 \\
\hline 12 & 67 & $M$ & s & yes & 45 & 5 & 18 & 7 & 25 & 25 & 17 & 12 \\
\hline 13 & 76 & $\mathrm{~F}$ & $S$ & no & 38 & 8 & 12 & 14 & 12 & 12 & 10 & 7 \\
\hline 14 & 73 & M & $S$ & no & 45 & 2 & 19 & 15 & 15 & 18 & 16 & 12 \\
\hline 15 & 75 & $M$ & $S$ & no & 27 & 2 & 10 & 10 & 4 & 5 & & \\
\hline 16 & 38 & $\mathrm{~F}$ & $S$ & no & 36 & 4 & 2 & 33 & 38 & 31 & & \\
\hline
\end{tabular}

Gen= gender; $M=$ male; $F=$ female; $P$ haco= phacoemulsification; Pre $I O P=$ pre-surgical intraocular pressure; IOP $48 \mathrm{hs}=$ intraocular pressure at 48 hours of surgery; $I O P$ 30, 60, 90, 120, 180, $360=$ intraocular pressure at $30,60,90,120,180,360$ days of surgery

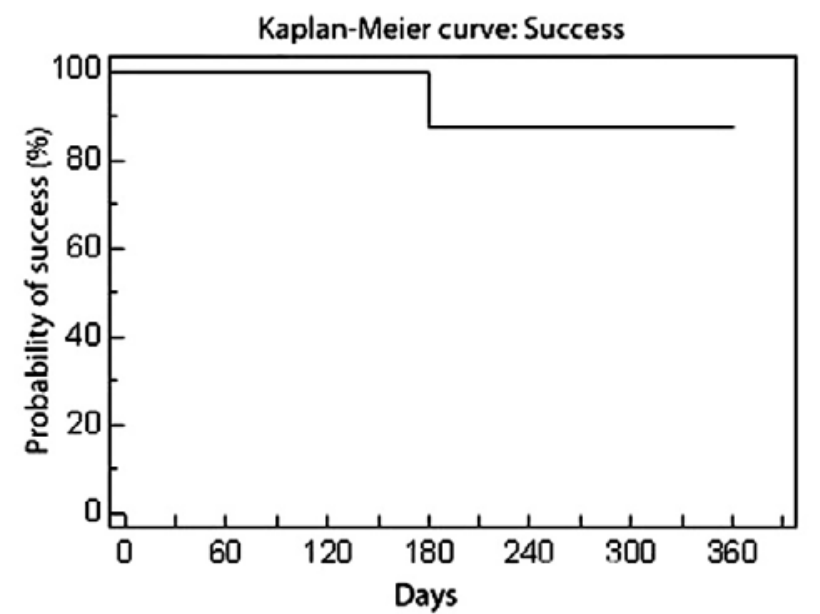

Figura 5. Kaplan-Meier curve: Probability of success. Criterion for success: IOP $\leq 21 \mathrm{mmHg}$.

Molteno and Krupin implants) that resolves within 3 to 6 months postoperatively ${ }^{(18)}$. These phenomena are apparently due to the formation and stabilization of the filtering bleb.

Some authors reported an incidence of hypertensive phase of $82 \%$. In these patients, it was necessary to perform needling techniques with injections of fluorouracil (5FU) (33\%) and/or surgical revision of the bleb or the placement of a second implant $(33 \%)^{(18)}$.

The hypertensive phase presented by these implants is the reason why some authors advise against its use in patients with severe optic nerve damage ${ }^{(18,19)}$.

The reason why the microdevice does not produce severe postoperative hypotony is that despite not presenting an intrinsic valve mechanism, the proper closure of the scleral flap regulates the exit of aqueous humor from the time of surgery.

There has been no case of hypertensive phase with the use of the microdevice.

The work of Ayala et al. ${ }^{(18)}$, showed that Tenon's tissue proliferation, described by Barraquer et al., as keloid type ${ }^{(20)}$, is a common denominator in the failure of glaucoma surgery. In the case of implants, this tissue grows around the plate and in the trabeculectomy, the NPDS or the microdevice, on the scleral flap. It is possible that surgical trauma, toxic effect of the aqueous humor to the conjunctiva ${ }^{(21)}$, the individual healing response, and the use of antiglaucomatous eye drops (patients with polypharmacy) are triggers of the formation of this tissue. Needling techniques (with or without injection of 5FU) used when the bleb is walled, and tenectomy (surgical resection of the keloid tissue) are procedures commonly used $^{(18)}$ to permeate the conjunctival bleb and resolve the excessive scarring in all filtering surgeries.

The results of this investigation show that the microdevice is safe in the treatment of refractory glaucoma as the complications presented are expected and inherent to any type of glaucoma surgery.

In terms of effectiveness, the success rate was 14 eyes $(87.5 \%, \mathrm{Cl}$ $95 \% 61.6 \%-98.6 \%)$. Overall, the findings support the hypothesis that the use of the microdevice was associated with a significant reduction of IOP. This was confirmed in the analysis of variance for repeated measures ( $F=37.891, P<0.0001)$.

In two out of 16 the microdevice failed $(12.5 \%$, Cl 95\% $1.43-38.4)$. Using confidence bands for projecting the population, it is expected that the maximum possible percentage of cases with negative response is $38.4 \%$ and the minimum of $1.43 \%$ with a confidence of $95 \%$.

Given that the pathology we are treating is defined as "refractory", it is to be expected that success may not be achieved in all cases.

\section{CONCLUSION}

It is important to note that the microdevice does not interfere with retinal buckling or alter extraocular motility as it is placed six millimetres from the limbus.

The use of the microdevice is partially contraindicated in patients with thin sclera, since the risk of extrusion is high. This contraindication is partial because, depending on the judgment and skill of the surgeon, it is possible to use the microdevice associated with scleral graft on the scleral flap.

\section{REFERENCES}

1. Lim KS, Allan BD, Lloyd AW, Muir A, Khaw PT. Glaucoma drainage devices; past, present, and future. Br J Ophthalmol. 1998;82(9):1083-9. Comment in: Br J Ophthalmol. 2005;89(4): 396-7.

2. Heuer DK, Lloyd MA, Abrams DA, Baerveldt G, Minckler DS, Lee MB, et al. Which is better? One or two? A randomized clinical trial of single-plate versus double-plate Molteno implantation for glaucomas in aphakia and pseudophakia. Ophthalmology. 1992;99(10): 1512-9.

3. Krupin eye valve filtering surgery. The Krupin Eye Valve Filtering Surgery Study Group. Ophthalmology. 1994;101(4): 651-8. Comment in: Ophthalmology. 1994;101(9):1477.

4. Fellenbaum PS, Almeida AR, Minckler DS, Sidoti PA, Baerveldt G, Heuer DK.. Krupin disk implantation for complicated glaucomas. Ophthalmology. 1994;101(7):1178-82. 
5. Lloyd MA, Baerveldt G, Heuer DK, Minckler DS, Martone JF. Initial clinical experience with the Baerveldt implant in complicated glaucomas. Ophthalmology. 1994;101(4):640-50.

6. Syed HM, Law SK, Nam SH, Li G, Caprioli J, Coleman A. Baerveldt-350 implant versus Ahmed valve for refractory glaucoma: a case-controlled comparison. J Glaucoma. 2004; 13(1):38-45

7. Fyodorov SN, Loffe DI, Ronkina TI. Deep sclerectomy: technique and mechanism of a new glaucomatous procedure. Glaucoma. 1984;3(6):281-3.

8. Zimmermann TJ, Kooner KS, Ford VJ, Olander KW, Mandlekorn RM, Rawlings FE, et al. Effectiveness of non penetrating trabeculectomy in aphakic patients with glaucoma. Ophthalmic Surg. 1984:15(1):44-50.

9. Arenas Archila E. Trabeculectomía ab externo. Highlights Ophthalmol. 1991;19:59-66.

10. Demailly P, Jeanteur-Leunel MN, Berkani M, Ecoffet M, Kopel J, Kretz G, et al. [Nonpenetrating deep sclerectomy combined with collagen implant in primary open angle glaucoma. Medium-term retrospective study]. J Fr Ophtalmol. 1996;19(11):659-66. French.

11. Koslov VI, Bagrov SN, Anisimova SY. Nonpenetrating deep sclerectomy with collagen. Moscow: RSFSR Ministry of Public Health; 1990. p.44-6.

12. Sampaolesi R, Sampaolesi J. Non-penetrating surgery for glaucoma. In: Innovations in the glaucomas: Etiology, diagnosis and management. Highlights Ophthalmol. 2002;24:225-44.

13. Maldonado Bas A, Maldonado-Junyent A. Filtering glaucoma surgery using an excimer laser. J Cataract Refract Surg. 2001;27(9):402-9.
14. Cairns JE. Trabeculectomy. Preliminary report of a new method. Am J Ophthalmol. 1968 66(4):673-9.

15. Vasco-Posada J. Glaucoma (esclerectomia subescleral). Arch Soc Am Ophthalmol Optom 1967;6:237-52

16. DSM Bright Science. Brighter living. Elasthane ${ }^{T M}$ thermoplastic polyether urethane [Internet] Berkeley, CA; 2011. [cited 2011 Jan 12]. Available from: http://www.dsm.com/en_US/html/ $\mathrm{dbm} /$ products_elasthane.htm

17. Tsai JC, Jhonson CC, Dietrich MS. The Ahmed shunt vs baerveldt shunt for refractory glaucoma: a single-surgeon comparison of outcome. Ophthalmology. 2003;110(9):1814-21.

18. Ayyala RS, Zurakowski D, Smith JA, Monshizadeh R, Netland PA, Richards DW, et al. A clinical study of the Ahmed glaucoma valve implant in advanced glaucoma. Ophthalmology. 1998;105(10):1968-76

19. Susanna R Jr.: Latin American Glaucoma Society Investigators. Partial tenon's capsule resection with adjunctive mitomycin $\mathrm{C}$ in Ahmed glaucoma valve implant surgery. $\mathrm{Br} J$ Ophthalmol. 2003;87(8): 994-8. Comment in: Br J Ophthalmol. 2003;87(8):932.

20. Barraquer J, Barraquer Rl, Canut MI, García Barberán I, Iglesias Touriño E, Kargachin Barraquer M, et al. Microcirugía de los glaucomas. Barcelona: Ed. Publicaciones del Instituto Barraquer; 1997.

21. Demailly P, Balon M, Béchetoille A, Castro D, Collignon J, Ecoffet M, et al. Traitement actue du glaucoma primitif à angle ouvert. Paris: Masson; 1989.

\title{
$14^{\circ}$ Congresso de Oftalmologia USP e $13^{\circ}$ Congresso de Auxiliar de Oftalmologia
}

\author{
$\mathbf{2 5}$ e $\mathbf{2 6}$ de novembro de 2011 \\ Centro de Convenções Rebouças \\ São Paulo - SP
}

\section{Informações:}

JDE Organização de Eventos

Tels.: (11) 5084-9174 e 5082-3030

Site: http://www.oftalmologiausp.com.br 